\title{
Research on Power Grid Fault Diagnosis Based on SVM
}

\author{
Huijun $\mathrm{Ni}^{1, a}$, Tianli $\mathrm{Ni}^{2, \mathrm{~b}}$ \\ ${ }^{1}$ Grid of China Technology College, Jinan, P.R.China \\ ${ }^{2}$ State Grid Shandong Jiyang Electric Power Company, including country

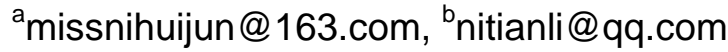

Keywords: Power Network, Fault Diagnosis, Support Vector Machine,SVM.

\begin{abstract}
By analyzing relative literatures and building a simulation model, this paper finishes the analyzing of fault waveforms and studies fault characteristics from the perspective of signal synthesis.With one-to-many SVM, the image extract features and features is identified to training Sample and recognizing sample.
\end{abstract}

\section{Introduction}

Recently, successive power blackouts of large scale occurred in the world, which attracts researchers' attention to the reliability of power grid.Power network fault diagnosis in our current electrical grid has been completed by experience with alert message on SCADA information platform. But it is difficulty for dispatchers to process warning message to analyse fault diagnosing in the condition of multi- complex fault. So using computer to process and diagnose power network faults automatically has become the inevitable demand.

\section{Literature Review}

With the complex of Power Network relay configuration, the change of Power network topology and all kinds of uncertainty, fault diagnosis and restoration of power network is a complicated, comprehensive issue. At present the information acquired by the fault diagnose of power system is mainly from the SCADA system based on relay operational information and breakers message.The diagnose difficulties substantially rises with false alarms and missing alarms about Power systems fault.logical relationship between circuit breaker relays and circuit-breaker protected was used to corrects most of the errors and add the missing information ${ }^{[1,2]}$. A lot of technique and theory of fault diagnosis in the power system have been proposed, such as expert system, artificial nerve net, Petri Net and Fuzzy theory. Fault section and fault type are estimated by using the information from protection relay and circuit breaker ${ }^{[3-6]}$.

\section{Analysis and Diagnosis on Power System Faults}

Analyze on Power System Faults. With matlab simulink simulation techniques, the wave of voltage and current under the most serious failure is obained, as shown in Figure 1-3 below.

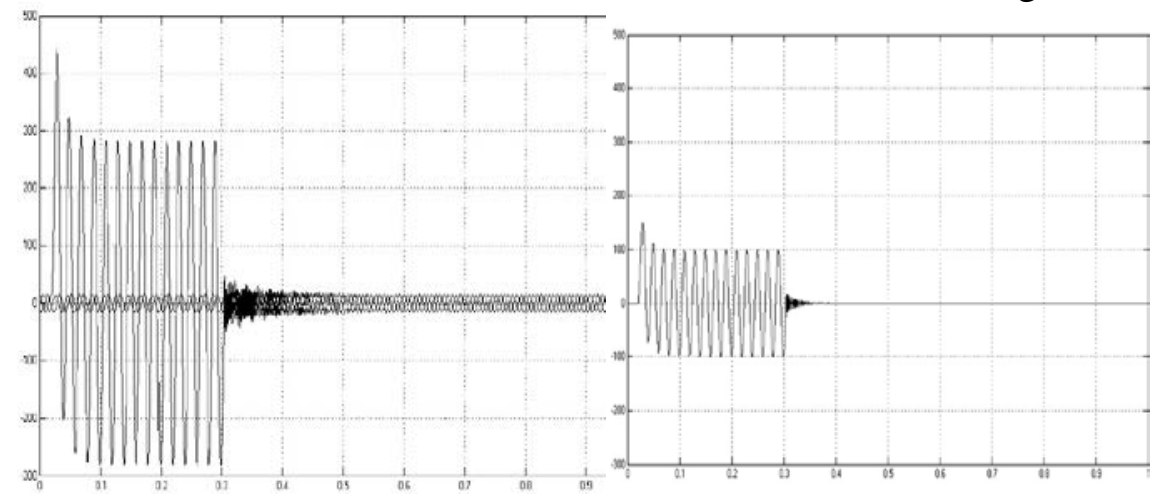
(1)A initial phase angle $0^{\circ}$
(2)Zero-sequence current, $\mathrm{A}$ initial phase angle $0^{\circ}$

Figu.1. Single phase earthing current 

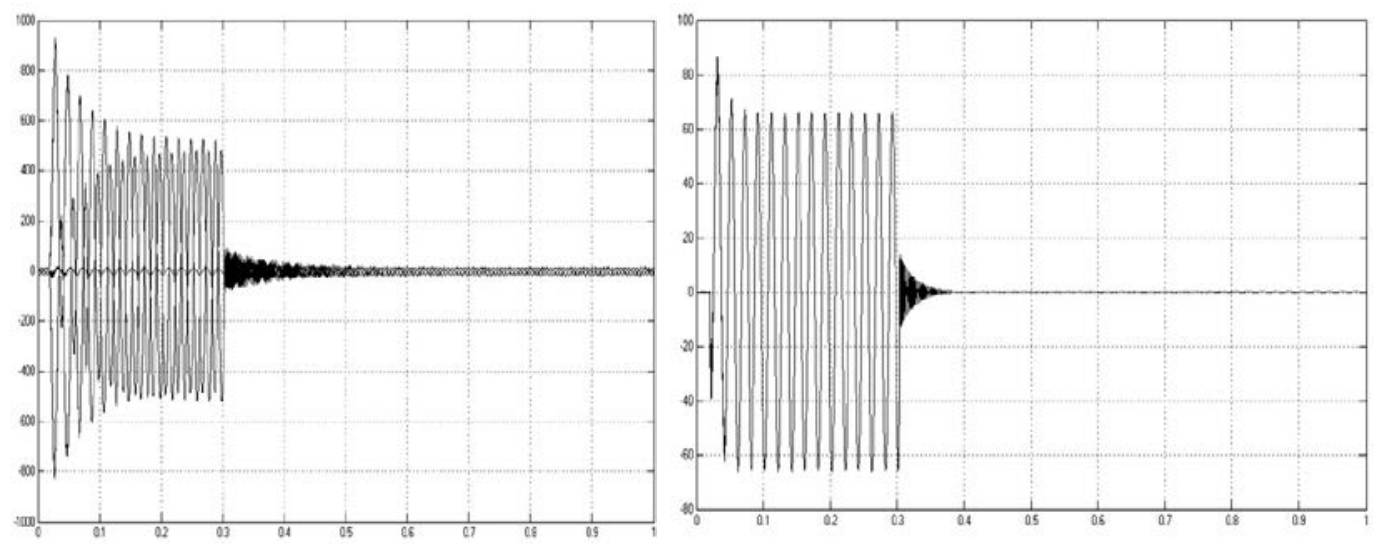

(1) A initial phase angle $0^{\circ}$

(2) Zero-sequence current, A initial phase angle $0^{\circ}$

Figu.2. Two phase-to-ground fault current
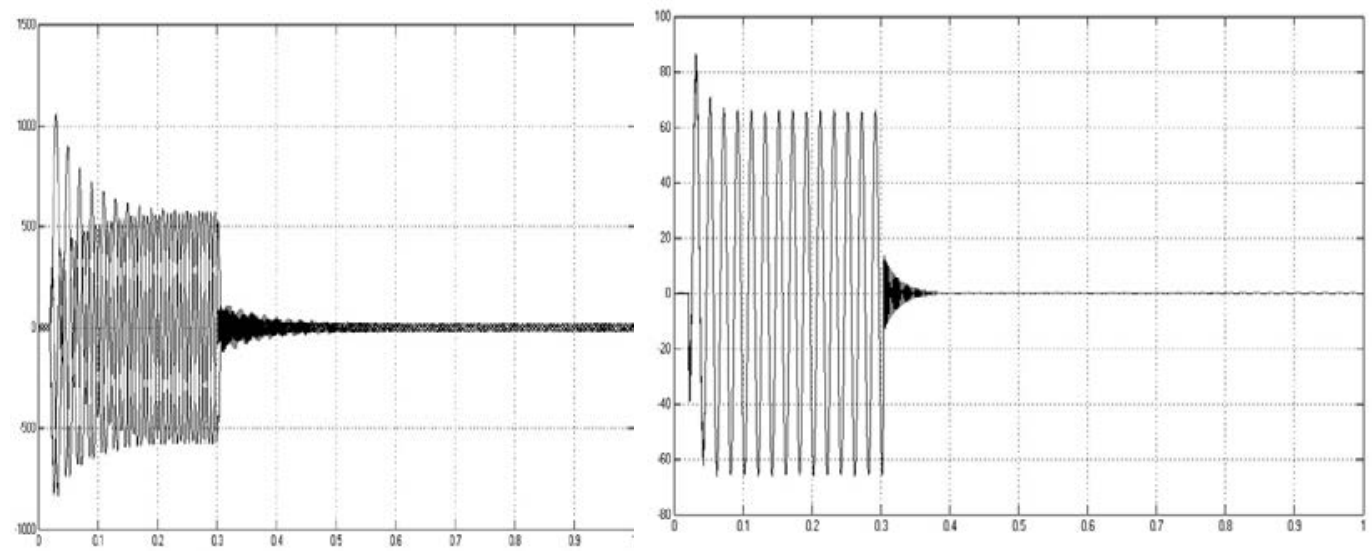

$\begin{array}{ll}\text { (1) A initial phase angle } 0^{\circ} & \text { (2) zero-sequence current, } \mathrm{A} \text { initial phase angle } 0^{\circ}\end{array}$ Figu.3. Three-phase short circuit fault current

By comparing fault current, Two phase-to-ground fault current is similar to single phase earthing current with double dash current. three-phase short circuit fault current is similar to single phase earthing current.

Synthesis and analysis on electrical signals wave. Wave is synthetized any two phase in the current signal in the vertical direction ideally as shown in Figure.4 below.

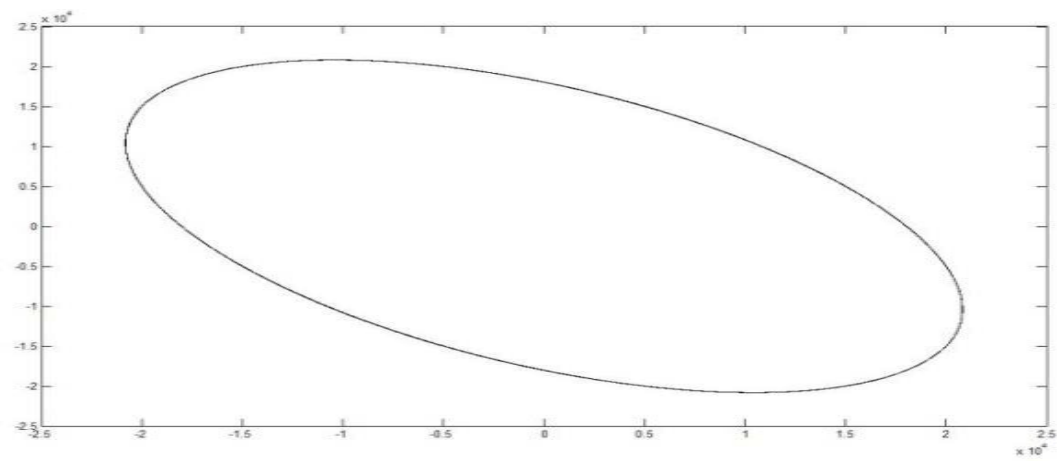

Figure. 4. Synthesis electrical signals wave ideally

Single phase earthing graphics is severely compressed in one direction, two phase-to-ground fault graphics is oblong shape, phases shortingault graphics turned out to be line on both sides close to the line with slope-1,three-phase short circuit fault graphics is scattered oval-shaped. as shown in Figure5(1)-(4). 


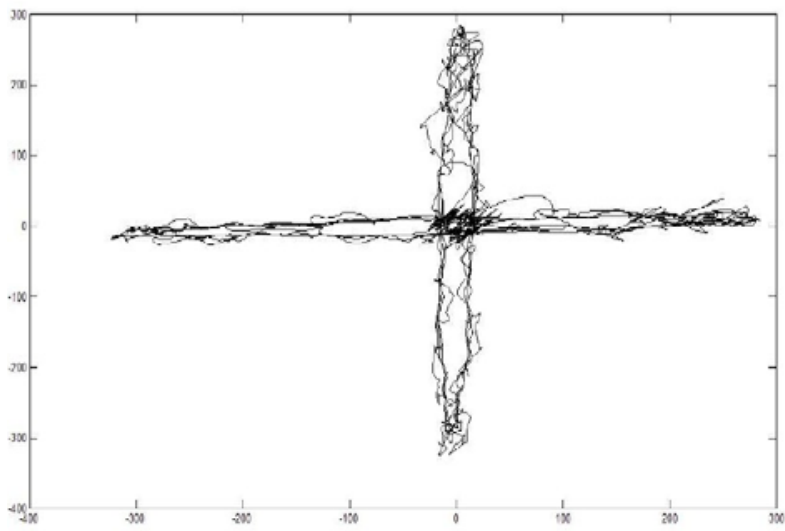

(1)Single phase earthing

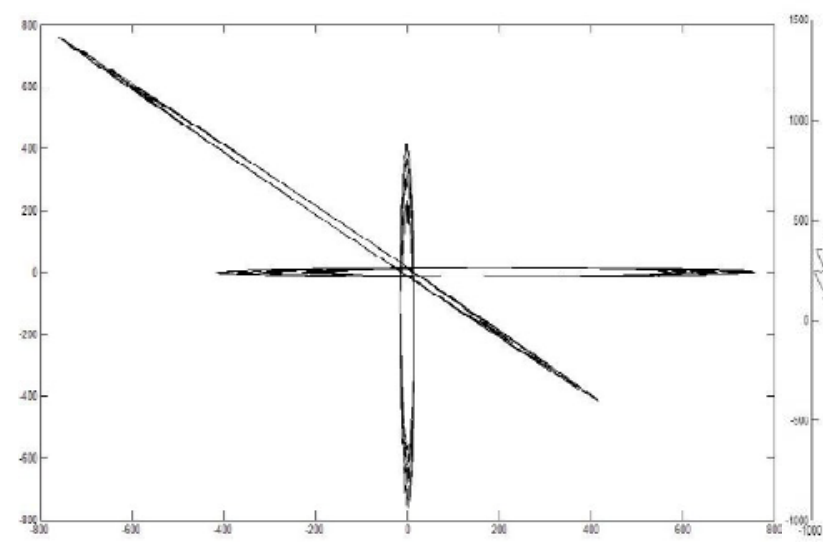

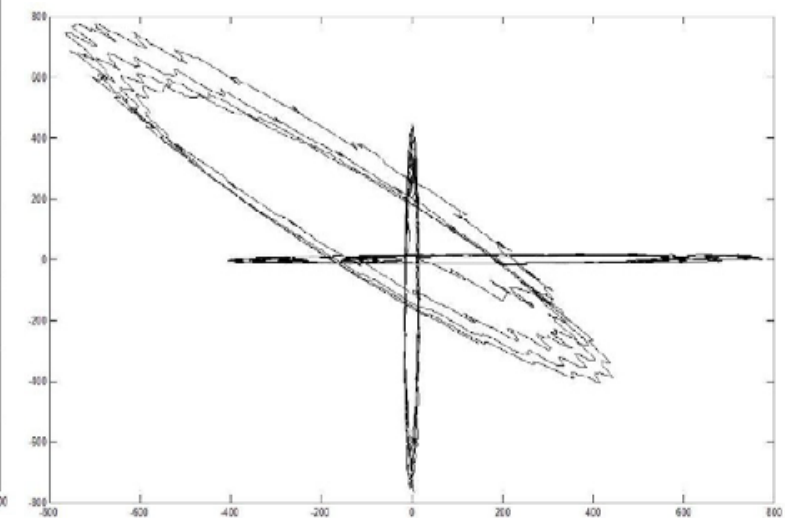

(2) Two phase-to-ground fault

(3)Phases shortingault

(4) Three-phase short circuit fault graphics

Figure. 5. Synthesis electrical signals wave

SVM-based Diagnosis on Power System Faults. After the above image feature extraction, a pair of SVM for recognition is used.The above image features is extracted and identified with oneto-many SVM. Training Sample and recognizing sample is displayed. Th amount of the training samplewith strong popularity is 154 , and The amount of the identification to discriminate the optimum assembly is 976 . Recognition results are as Tab.1. follows.

Tab.1. The kernel and its parameters

\begin{tabular}{l|l|l|l}
\hline The kernel parameters & test precision & test rate & training speed \\
\hline Linear,c=200,coef0=0 & $100.0 \%$ & $0.000772 \mathrm{~s}$ & $0.002577 \mathrm{~s}$ \\
\hline Polynomial, c=200, coef0=0,d=3 & $100.0 \%$ & $0.000773 \mathrm{~s}$ & $0.002615 \mathrm{~s}$ \\
\hline Rbf, c=200, gamma $=0.5$ & $65.71 \%$ & $0.002407 \mathrm{~s}$ & $0.011358 \mathrm{~s}$ \\
\hline Rbf, c=200, gamma $=0.01$ & $81.43 \%$ & $0.003015 \mathrm{~s}$ & $0.012062 \mathrm{~s}$ \\
\hline Rbf, c=200, gamma $=0.001$ & $88.57 \%$ & $0.002367 \mathrm{~s}$ & $0.011851 \mathrm{~s}$ \\
\hline Rbf, c=200, gamma $=0.0001$ & $98.57 \%$ & $0.001845 \mathrm{~s}$ & $0.008431 \mathrm{~s}$ \\
\hline Rbf, c=200, gamma=0.00001 & $100.0 \%$ & $0.001389 \mathrm{~s}$ & $0.003544 \mathrm{~s}$ \\
\hline Sigmoid, c=200, gamma=0.5,coef0=0 & $11.43 \%$ & $0.002148 \mathrm{~s}$ & $0.006984 \mathrm{~s}$ \\
\hline Sigmoid, c=200, gamma=1e-02, coef0=0 & $7.14 \%$ & $0.002683 \mathrm{~s}$ & $0.007562 \mathrm{~s}$ \\
\hline Sigmoid, c=200, gamma=1e-03, coef0=0 & $4.286 \%$ & $0.002620 \mathrm{~s}$ & $0.007472 \mathrm{~s}$ \\
\hline
\end{tabular}




\begin{tabular}{l|l|l|l}
\hline Sigmoid, c=200, gamma=1e-04, coef $0=0$ & $14.29 \%$ & $0.002719 \mathrm{~s}$ & $0.006217 \mathrm{~s}$ \\
\hline Sigmoid, c=200, gamma=1e-05, coef0 $=0$ & $32.86 \%$ & $0.002446 \mathrm{~s}$ & $0.004396 \mathrm{~s}$ \\
\hline Sigmoid, c=200, gamma=1e-06, coef0 $=0$ & $72.86 \%$ & $0.001528 \mathrm{~s}$ & $0.002956 \mathrm{~s}$ \\
\hline Sigmoid, c=200, gamma=1e-07, coef $0=0$ & $82.86 \%$ & $0.001697 \mathrm{~s}$ & $0.004553 \mathrm{~s}$ \\
\hline Sigmoid, c=200, gamma=1e-08, coef0 $=0$ & $57.14 \%$ & $0.002333 \mathrm{~s}$ & $0.005293 \mathrm{~s}$ \\
\hline Sigmoid, c=200, gamma=1e-07, coef0 $=0.1$ & $82.86 \%$ & $0.001804 \mathrm{~s}$ & $0.003981 \mathrm{~s}$ \\
\hline Sigmoid, c=200, gamma=1e-07, coef0=-0.1 & $82.86 \%$ & $0.001994 \mathrm{~s}$ & $0.004179 \mathrm{~s}$ \\
\hline
\end{tabular}

\section{Conclusion and discussion}

The paper analyses and identifies synthesis image data of fault current based on research grid failures characteristics with SVM, gives a new method to diagnose and restorate fault of power network. Compared with other neural networks, simulation results show that the SVM-based method has higher accuracy and faster rapidity for the recognition. It is a practical approach for engineering application to overcome defects sensitive to initialization and easy fallen to local minimum.

The future research direction includes: one, when a fault occurs in a power system wiht some more mixed statistics, multi-source information fusion is a effective solution conducting information coming from multiple sources with multi-level, multifaceted, multi-level processing to generate new and meaningful information. Two, with the scale of power system larger and larger, the whole power system gets more and more complicated, several data fusion methods instead of the simple means is one important field of studies.

\section{References}

[1] Juhvvan Jung, Chen-Ching Liu, Mingguo Hong,IEEE Transactions on Power Delivery,Vol.16 (2001),p.225-230.

[2] Jung J, Hong M G, LIU C C, et al., In:ISAP'99. Rio de Janeiro(Brazil)(1999).

[3] Wen F S,Chang C S:IEE Proceedings-Generation and Distribution,Vol.145(6) (1998),p.722-730.

[4] Ernesto Vazquez M, Oscar L,chacon M, et al. IEEE Transactions on Power System, Vol.12(1997), p.357-362.

[5] Young Moon Park, Gvvang-Won Kim, Jin-Man Sohn, IEEE Transactions on Power System, Vol.12(1997), p.363-369.

[6] Hong-Tzer Yang, Wen-Yeau Chang, Ching-Lien Huang. IEEE Transactions on Power System, Vol.10(1995), p.323-331. 